\title{
Wort fermentation and beer conditioning with selected non- Saccharomyces yeasts in craft beers
}

\author{
M. J. Callejo ${ }^{1}$ (D) J. J. García Navas ${ }^{1} \cdot$ R. Alba ${ }^{1} \cdot$ C.. Escott $^{1}$ - I. Loira ${ }^{1} \cdot$ M. C. González ${ }^{1}$ A. Morata ${ }^{1}$
}

Received: 12 July 2018 / Revised: 5 December 2018 / Accepted: 8 December 2018 / Published online: 5 February 2019

(c) Springer-Verlag GmbH Germany, part of Springer Nature 2019

\begin{abstract}
The use of non-Saccharomyces yeasts means a great source of biodiversity for the production of differentiated beer products. With this objective, five species of different genera have been selected in order to evaluate their influence on beer quality. Two different experiments were carried out with four non-Saccharomyces strains (Schizosaccharomyces pombe, Torulaspora delbrueckii, Saccharomycodes ludwigii and Lachancea thermotolerans) and Saccharomyces cerevisiae, as control. In the first experimental setup, the five strains were used to carry out the pure culture wort fermentation and to undertake bottle conditioning. In a second experimental setup, the wort was fermented with S. cerevisiae and the four non-Saccharomyces strains were used for bottle conditioning. Beers from the first experimental setup had low ethanol content due to the wort's original gravity; $T$. delbrueckii produced a beer with the largest quantity of isoamyl acetate. In the second setup, the wort had higher original gravity; most of the fermentative volatiles were produced in larger amounts (1-propanol, isobutanol, 2-methyl-1-butanol, 3-methyl-1-butanol) with all tested strains. The differences observed in the volatiles production were more pronounced when the yeast strains were used for the fermentation and the bottle conditioning than whey they were used just for the bottle conditioning. The species $S$. pombe produced a significantly higher ethanol concentration (\%v/v) in both experimental setups; these beers also obtained the highest scores for the sensory attributes foam consistency and foam persistence. Beers produced with T. delbrueckii and S. ludwigii had low ethanol content in both experimental designs, in pure culture fermentation and in bottle conditioning.
\end{abstract}

Keywords Craft beers $\cdot$ Non-Saccharomyces $\cdot$ Fermentative volatiles $\cdot$ Bottle conditioning

\section{Introduction}

Nowadays, there is a growing interest for beer production in several countries and craft brewing, an alternative to mainstream beer, have re-emerged. Craft brewing is a term that applies to relatively small breweries, which production aimed at maintaining original sensory characteristics on the basis of quality and diversity. A variety of off-flavours in craft beers increase their probability of being perceived as having a higher quality than commercial beer [1]

\section{J. Callejo}

mj.callejo@upm.es

1 Chemistry and Food Technology Department, School of Agricultural, Food and Biosystems Engineering, Universidad Politécnica de Madrid, Campus Ciudad Universitaria, Av. Puerta de Hierro, nº 2-4, 28040 Madrid, Spain
Although there are various options for obtaining different sensory profiles among beers (using special malts or adjuncts, hop varieties, water quality, etc.), the choice of yeast strains for wort fermentation and beer conditioning is crucial. The production of most aroma-active compounds is strictly dependent on the yeast strain chosen for the fermentation [2,3].

Considering that craft beers are generally unfiltered, unpasteurized and conditioned in bottle [4,5], selection of suitable strains is a good important choice to producing good beer. In addition, the use of aromatic-enhancing microorganisms offers the advantage of being a natural and sustainable solution that does not negatively influence the list of ingredients [6]. The use of $S$. cerevisiae yeast strains isolated from food matrices such as wine [7] or bread [7, 8], as starters for craft beer production is gaining interest. On the other hand, the highly developed use of non-Saccharomyces yeasts in oenology is still a very unknown concept in brewing and it opens up new possibilities compared to traditional $S$. 
cerevisiae strains [9]. Although non-Saccharomyces yeasts have been widely disregarded due to their possible overproduction of acetic acid and other off-flavour compounds, they can potentially exert positive influences on beer flavour through the generation of secondary metabolites with significant organoleptic impact and excretion of enzymes responsible for the bioconversion of non-volatile precursors into desirable aroma compounds [10].

Today, Dekkera/Brettanomyces, isolated from spontaneous brewing processes, are the most relevant non-Saccharomyces yeasts in the production of sour beers, mainly because of the discovery of its singular influence in Lambic beers [11]. American craft brews are using Dekkera spp. for fermentations [12], due to a complex aroma profile perception that is described including clove, barnyard, smoke, humid leather, tropical fruit, and/or spices; T. delbrueckii strains traditionally used in the production of Bavarian wheat beers (Hefeweizen) [13] can grow-even with an increase in the lag-phase-in the presence of up to $90 \mathrm{ppm}$ isoo-acids in the medium, a concentration that correlates to highly hopped beer styles [11]. Some studies have investigated the contributions of $T$. delbrueckii in beer, where it has proven to reveal important characteristics, both in pure and mixed fermentations with $S$. cerevisiae, producing low-alcohol beers with pleasant and aromatic flavours [5, 13]; S. ludwigii and Zygosaccharomyces rouxii are unable to ferment maltose and are used for the industrial production of low-ethanol or alcohol-free beer entailing inhibition of alcohol production via biological processes [12]. There have been extensive studies of Lachancea thermotolerans in wines for its ability to reduce $\mathrm{pH}$ and volatile acidity and increase glycerol in co-inoculations with $S$. cerevisiae [14, 15]. In beer, it has been observed that $L$. thermotolerans can produce lactic acid, which enables the production of sour beers without the need to use bacteria, shortening the process and affecting the taste and sensation in the mouth [16].

The aim of the present study was to evaluate the feasibility of the use of different strains of non-Saccharomyces yeast (S. pombe, T. delbrueckii, S. ludwigii and L. thermotolerans) as starters for craft beer production at a microbrewery scale during both wort fermentation and bottle conditioning. The volatile profiles of the beer samples were evaluated by instrumental and sensory analysis.

\section{Materials and methods}

\section{Yeast strains}

The 6 yeast strains used in this study belong to the species: Saccharomyces cerevisiae (as control) (7VA Yeast Collection of Dpto. Química y Tecnología de Alimentos Universidad Politécnica de Madrid UPM (Spain), Saccharomyces cerevisiae commercial strain (Florapan ${ }^{\circledR}$ A18, Lallemand), Schizosaccharomyces pombe (938 Yeast Collection of the Instituto de Fermentaciones Industriales IFI (Spain), Torulaspora delbrueckii (291 Lallemand), Saccharomycodes ludwigii (979 Yeast Collection of the IFI (Spain), and Lachancea thermotolerans (kt 421 Hansen). Non-Saccharomyces yeasts were used because of their specific features: S. pombe 938 have been used in sole and mixed fermentations improving aroma production, deacidification and colour stability $[17,18]$. Torulaspora delbrueckii 291 was used by the low volatile acidity production and the aroma enhancement [19]. Saccharomycodes ludwigii 979 was studied by the release of cell wall polysaccharides and fermentative power [20]. Lachancea thermotolerans 421 was due to the acidification properties and aroma enhancement [21]. Saccharomyces cerevisiae strains were used as controls to compare. C. cerevisiae 7VA has low production of volatile acidity and strong fermentative power [19]. The ability of these yeast strains to ferment maltose and maltotriose was evaluated in liquid growing YEPM media with yeas extract (1\%), peptone (2\%) and maltose or maltotriose (2\%). A Durham's tube indicated the production of $\mathrm{CO}_{2}$ from the metabolic processes by each strain. The summary of the observed results is shown in Table 1.

Two experimental setups (labelled A and B) were carried out (Fig. 1). In the first experiment (Experiment A), the fermentation of the wort and the bottle conditioning were done with each of the five strains as pure culture (7VA, 938, 291, 979, kt 421). In the second experiment (Experiment B), a mixed culture was used: first fermentation of the wort was made with a Lallemand's commercial strain $S$. cerevisiae (Florapan ${ }^{\circledR}$ A18 which is a special strain of beer yeast with a round and complex flavour contribution. http://www.lalle mandbaking.com/products/cultured-flours/) and the conditioning took place in the bottle after adding inoculums of each of the five strains (7VA, 938, 291, 979, kt 421).

For short-term storage, YPD agar medium ( $1 \%$ yeast extract, $2 \%$ peptone, $2 \%$ glucose, $1.8 \%$ agar; all w/v) (Oxoid, Basingstoke, UK) at $4{ }^{\circ} \mathrm{C}$ was used across all yeast strains,

Table 1 Maltose and maltotriose fermentation ability by the six evaluated yeast strains

\begin{tabular}{lll}
\hline Yeas strain & $\begin{array}{l}\text { Maltose fer- } \\
\text { mentation }\end{array}$ & $\begin{array}{l}\text { Maltotriose } \\
\text { fermenta- } \\
\text { tion }\end{array}$ \\
\hline Florapan ${ }^{\circledR}$ A18 & +++ & - \\
7VA Saccharomyces cerevisiae & +++ & - \\
938 Schizosaccharomyces pombe & +++ & - \\
291 Torulaspora delbrueckii & + & - \\
979 Saccharomycodes ludwigii & - & - \\
kt 421 Lachancea thermotolerans & + & - \\
\hline
\end{tabular}

+++ strong fermentation, + weak fermentation 


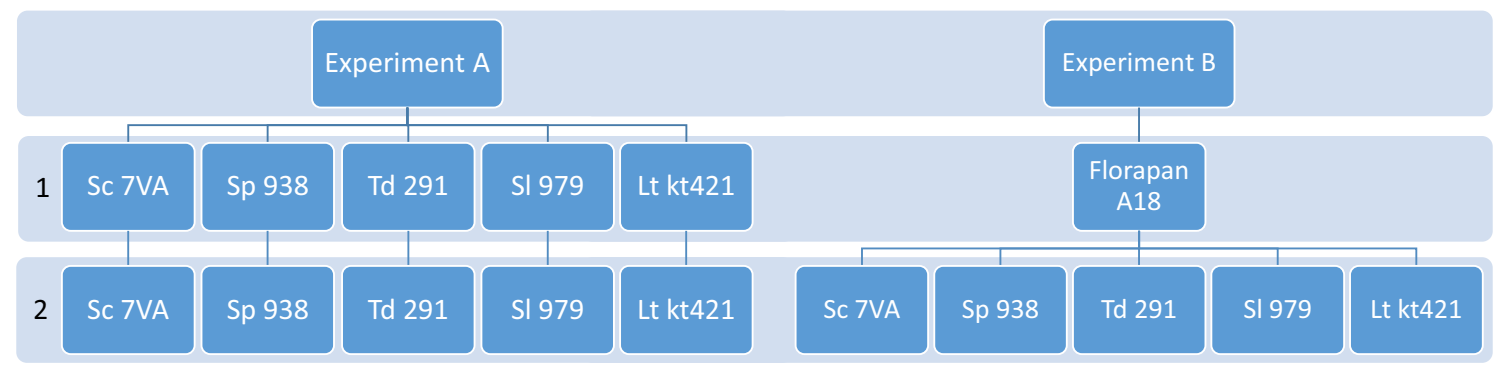

Fig. 1 Experimental design of the two setups: first fermentation (1) and bottle conditioning (2)

while for long-term storage, YPD broth supplemented with $80 \%(\mathrm{w} / \mathrm{v})$ glycerolat $-80{ }^{\circ} \mathrm{C}$ was used.

\section{Brewing process}

Wort production. The specific wort employed for the microfermentation trials was produced by means of a $25-\mathrm{L}$ pilotscale brewing plant (Braumeister, Speidel, Ofterdingen, Germany).

The malt used in each experiment was crushed in a Brewferm hand iron malt mill, leaving part of the whole grain husk: for experiment A $4 \mathrm{~kg}$ (40\% Pilsen type/60\% wheat malt) were prepared, and for Experiment B, $4.4 \mathrm{~kg}(97.8 \%$ Pilsen type $/ 2.2 \%$ coloured malt $(900 \pm 100$ EBC) were obtained. The grist was mixed in a 27-L capacity Brewferm ${ }^{\circledR}$ stainless steel pot to begin the mashing process. The wort was boiled with $13 \mathrm{~g}$ Hallertauer hop (Experiment A)/21.4 g Nugget hop (Experiment B) and then cooled at $20{ }^{\circ} \mathrm{C}$. The initial density of the wort was 1020 for Experiment A and 1060 for Experiment B.

Suspensions of cells in water, characterized by an absorbance $\mathrm{A} 580=0.5$, which corresponds to an average cell concentration of $10^{6}$ cells per millilitre, were obtained for all of the yeast strains. Wort was pitched with $10 \times 10^{6}$ yeast cells per millilitre and fermented for 10 days at $20^{\circ} \mathrm{C}$.

Two different protocols were tested in triplicate:

Experiment $A$. The same yeast strain was inoculated in both primary wort fermentation and bottle conditioning. Primary fermentation was performed in five 3-L volume sterilized Erlenmeyer flasks. Each of the different yeast strains, $S$ cerevisiae (7VA), S. pombe (938), T. delbrueckii (291), S. ludwigii (979) and L. thermotolerans (kt 421) were inoculated in a flask. The bottle conditioning was carried out in glass bottles with a 0.33 -L capacity, amber colour, corona stopper, standard model, adding $5 \mathrm{~g} \mathrm{~L}^{-1}$ sucrose and inoculated with each of the same five strains $\left(1 \times 10^{6} \mathrm{CFU} \mathrm{mL}^{-1}\right)$.

Experiment B. A special beer strain yeast $S$. cerevisiae Florapan A18 was inoculated in primary wort fermentation. At the end of the fermentation process, the green beer had a density of 1016 and was transferred into $0.33 \mathrm{~L}$ bottles, adding $5 \mathrm{gL}^{-1}$ sucrose and inoculated with the five strains $\left(1 \times 10^{6} \mathrm{CFU} \mathrm{mL}^{-1}\right)$ : $S$. cerevisiae (7VA), S. pombe (938), T. delbrueckii (291), S. ludwigii (979) and L. thermotolerans (kt 421). The bottle conditioning was carried out in glass bottles with a 0.33 -L capacity, amber colour, corona stopper, standard model.

The bottle conditioning was carried out at $18-20{ }^{\circ} \mathrm{C}$ for 25 days. After this period, the beers underwent sensory analysis.

\section{Sensory analyses}

Sensory analyses were carried out by means of sensory profile analysis tests ISO 6564: 1985 [22] and ISO 4121: 2003 [23]. In this way the scores of the different attributes presented in the tasting chart were obtained, for each of the beers, by each judge on the panel (eight males and four females). At each tasting station, there was a small white tablecloth and five tasting glasses with the samples being evaluated. Likewise, the judges all had a glass of water each. A code was assigned to each type of beer according to the yeast strain inoculated. The attributes to be analysed were classified into three groups: appearance, smell and taste. For each attribute, judges scored from 0 to 10 on an unstructured hedonic scale, with 0 being the lowest value and 10 being the highest.

For appearance, effervescence was determined referring to the intensity of the $\mathrm{CO}_{2}$ flow in the beer matrix, with a low intensity receiving the lowest value and a high intensity, the highest value; turbidity, was rated depending on the range of transparency with opaque receiving the highest value on a sliding scale; the consistency of the foam, related to the size of the bubble, very light in the case of large bubbles for the lowest value and creamy in case of small bubbles for the highest value; the persistence of the foam, depending on the duration of the foam, between low duration and high duration; and the colour of the foam, in a range of intense white for the lowest value and brown for the highest value.

For olfaction parameters, malt, yeast, caramel, banana and hops were analysed, the lowest value being a slight or absent odour and the highest value an intense odour for each one. For taste, we examined bitterness, sweetness, acidity, 
body, astringency and aftertaste, with a range of mild or absent tastes receiving the lowest value and a strong or intense taste, the highest. Finally, a comments section for each type of beer was offered. To enable a results comparison, a radar diagram was elaborated with the average values for each beer type.

After completion of the sensory tasting, beer samples were poured into $50 \mathrm{ml}$ amber glass flasks and were stored at $4{ }^{\circ} \mathrm{C}$ before the instrumental analysis.

\section{pH determination}

The $\mathrm{pH}$ of each sample was measured with a Crison micropH $2000 \mathrm{pH}$ meter. The results were collected in a table and plotted on a column chart.

\section{Determination of alcohol content by HPLC-RI}

The ethanol content in beer was analysed with a Waters e2695 Alliance liquid chromatograph (Waters, Massachusetts, USA) equipped with a refractive index detector 2414 and a photodiode array detector 996. MilliQ water was used as the solvent with a flow rate of $0.4 \mathrm{~mL} / \mathrm{min}$ in isocratic mode. $200 \mu \mathrm{m}$ of each beer sample was removed for pre-filtering through $0.45 \mu \mathrm{m}$ pore size cellulose ester filters (Teknokroma, Barcelona, Spain) and then a total of 25 samples were injected into the HPLC apparatus. Separation of the analytes was carried out on a $\mathrm{C} 18$ PhenoSphere XDB reverse phase column $(150 \times 4.6 \mathrm{~mm}, 5 \mu \mathrm{m}$ particle size) (Phenomenex, California, USA) stabilized at $30{ }^{\circ} \mathrm{C}$. Quantification was performed with ethanol (99.5\% purity) (Panreac, Spain) as an external standard with four calibration levels: 5, 10, 15 and $20 \% \mathrm{v} / \mathrm{v}\left(r^{2}=0.9734\right)$. The injection volume was $2 \mu \mathrm{l}$. The data were collected in a table and the mean value of each species was calculated for comparison.

\section{Determination of by-products and volatile compounds by GC-FID}

For the sample preparation, $1 \mathrm{ml}$ of each beer sample was filtered using $0.45 \mu \mathrm{m}$ pore size cellulose ester filters (Teknokroma, Barcelona, Spain) and $100 \mu$ of internal standard was added (concentration $500 \mathrm{mgl}^{-1}$ ) to each.

Aromatic profiles of the beer were determined by GC-FID using an Agilent Technologies 6850 gas chromatograph (GC System Network) equipped with an integrated flame ionization detector (GC-FID) (Hewlett-Packard, Palo Santo, CA, US). A DB-624 column $(60 \mathrm{~m} \times 250 \mathrm{~mm} \times 1.4 \mathrm{~mm})$ was used, calibrated with compounds as external standards: acetaldehyde, methanol, 1-propanol, diacetyl, ethyl acetate, 2-butanol, isobutanol, 1-butanol, acetoin, 2-methyl-1-butanol, 3-methyl-1-butanol, ethyl lactate, isobutyl acetate, 2,3-butanediol, isoamyl acetate, 2-phenylethyl acetate and 2-phenylethyl alcohol. Similarly, 4-methyl-2-pentanol was used as an internal standard (all compounds of Fluka, SigmaAldrich Corp., Buchs SG, Switzerland). The temperature of the injector was $250{ }^{\circ} \mathrm{C}$ and the detector was $300{ }^{\circ} \mathrm{C}$. The column temperature was $40{ }^{\circ} \mathrm{C}$ for the first $5 \mathrm{~min}$, progressively increasing at $10^{\circ} \mathrm{C} / \mathrm{min}$ intervals to $250{ }^{\circ} \mathrm{C}$, with the latter remaining constant for $5 \mathrm{~min}$. Hydrogen was used as the carrier gas. A microliter per sample was injected into the gas chromatograph. The limit of detection was $0.1 \mathrm{mg} / \mathrm{l}$.

\section{Statistical analysis}

The means, standard deviations were calculated and the differences were examined by analysis of variance (ANOVA) and the least significant difference test (LSD). All calculations were performed using Statgraphics software v.16.2.04 (Graphics Software System, Rockville, MD, United States). Significance was set at $p<0.05$. Five replicates were made for each yeast species for the measurement of $\mathrm{pH}$, ethanol and by-products, and volatile compounds and 12 replicates for sensory analysis. In order to highlight the similarities and differences between the obtained results, a principal component analysis (PCA) was carried out on the analytical data.

\section{Results}

Wort density at the beginning of the first fermentation (original gravity) was quite different in the two experiments (A and $\mathrm{B}$ ), probably due to the lack of water evaporation during boiling in Experiment A, therefore resulting in a low concentration in the wort. Table 2 shows the original gravity $\left({ }^{\circ} \mathrm{P}\right)$ of the wort in both experiments, $\mathrm{A}$ and $\mathrm{B}$, as well as the $\mathrm{pH}$ and the ethanol content $\left(\mathrm{mg} \mathrm{l}^{-1}\right)$ in the beer produced by the five yeast strains in the same two experiments.

The final values of original gravity were $5^{\circ} \mathrm{P}$ in Experiment $\mathrm{A}$ and $15^{\circ} \mathrm{P}$ in Experiment $\mathrm{B}$. In this way, the original gravity obtained in Experiment $\mathrm{A}$ is according to what Branyik et al. [24] have described for stopped or limited fermentation processes (between 4.0 and $7.5 \mathrm{wt}$ ).

The $\mathrm{pH}$ values measured in beers ranged from 3.8 to 4.7; these values are within the range found by Polshin et al. [25] after analysing the physicochemical parameters of $50 \mathrm{Bel}-$ gian and Dutch beers. According to them the $\mathrm{pH}$ of the beers ranged between 3.35 and 4.56 .

The original gravity measured in the worts yielded ethanol volumes with significant differences for each of the five beers elaborated in both experiments; ethanol content in Experiment A reached values from $0.5 \pm 0$ to $2.2 \pm 0.1$ $(\% \mathrm{v} / \mathrm{v})$ (values close to those of alcohol-free and low-alcohol beers), while beers in Experiment B produced ethanol between $6.7 \pm 0$ and $8.1 \pm(\% \mathrm{v} / \mathrm{v})$. 
Table 2 Original gravity $\left({ }^{\circ} \mathrm{P}\right), \mathrm{pH}$ and ethanol content $\left(\mathrm{mg} \mathrm{l}^{-1}\right)$ in the beer produced by the five yeast strains in both experiments, A and $\mathrm{B}$

\begin{tabular}{lllllll}
\hline Experiment & & S. cerevisiae 7VA & $\begin{array}{l}\text { S. pombe } \\
938\end{array}$ & $\begin{array}{l}\text { T. delbrueckii } \\
291\end{array}$ & $\begin{array}{l}\text { S. ludwigii } \\
979\end{array}$ & $\begin{array}{l}\text { L. thermotolerans } \\
\mathrm{kt} 421\end{array}$ \\
\hline A & Original gravity & 5 & & & & \\
& $\mathrm{pH}$ & $4.1 \pm 0.0^{\mathrm{b}}$ & $3.8 \pm 0.1^{\mathrm{a}}$ & $4.6 \pm 0.1^{\mathrm{d}}$ & $4.7 \pm 0.1^{\mathrm{d}}$ & $4.3 \pm 0.0^{\mathrm{c}}$ \\
& Ethanol & $1.9 \pm 0.0^{\mathrm{bc}}$ & $2.2 \pm 0.1^{\mathrm{c}}$ & $0.5 \pm 0.0^{\mathrm{a}}$ & $0.6 \pm 0.1^{\mathrm{a}}$ & $1.4 \pm 0.8^{\mathrm{b}}$ \\
& Original gravity & 15 & & & $4.08 \pm 0.02^{\mathrm{a}}$ & $4.10 \pm 0.01^{\mathrm{a}}$ \\
& $\mathrm{pH}$ & $4.11 \pm 0.03^{\mathrm{a}}$ & $4.28 \pm 0.06^{\mathrm{b}}$ & $4.09 \pm 0.01^{\mathrm{a}}$ & $6.7 \pm 0.1^{\mathrm{a}}$ & $6.8 \pm 0.0^{\mathrm{a}}$ \\
\hline
\end{tabular}

Data are means \pm standard deviations $(n=3)$

Data with different superscript letters within each row are significantly different (Tukey tests: $P<0.05$ ); A: the same yeast strain was inoculated in both primary fermentation and bottle conditioning; B: S. cerevisiae Florapan A18 was used in primary fermentation. The bottle conditioning was performed with the five yeast strains

Schizosaccharomyces pombe produced the highest amount of ethanol (\%v/v) (Table 2) in both experiments; this fact evidences the high fermentative power of this strain in comparison to the other tested strains. Pure culture fermentation followed by bottle conditioning with $S$. pombe in Experiment A had a significant lower $\mathrm{pH}$ value $(3.8 \pm 0.1)$, while the same strain used for bottle conditioning in Experiment $\mathrm{B}$ had the significant highest $\mathrm{pH}$ value $(4.28 \pm 0.06)$.

Concentration of the average values for volatile compounds produced by the five yeast strains in both experiments, A and B, can be seen in Table 3. Even though the volatiles concentration is higher in beers where the yeasts were used just for bottle conditioning (Experiment B), there are, in many volatile compounds, more pronounced differences between strains were observed when the yeast strains were used for pure culture fermentations and bottle conditioning (Experiment A). The concentration of acetaldehyde had significant higher values in beers produced with $S$. pombe in both experiments (A and B) (green, herbal aroma); the highest value (20.6 mg 1-1) was observed in Experiment B where S. pombe was used for bottle conditioning. On the other hand, beers produced with T. delbrueckii and S. ludwigii in Experiment B, yielded the lowest ethanol content when used for bottle conditioning.

Regarding diacetyl content, all samples from Experiment A, with the exception of that fermented with $S$. cerevisiae, had concentrations higher than its perception threshold of $0.15 \mathrm{ppm}$; in Experiment B, all tested strains apart from $S$. ludwigii produced larger diacetyl amounts when used only for bottle conditioning. S. ludwigii produced the highest amount of diacetyl in Experiment A, while in Experiment $\mathrm{B}$, species $L$. thermotolerans reached the largest values.

In terms of 2,3-butanediol production, the concentration of this compound is greater in Experiment B, and so too with diacetyl; despite this fact, none of the samples reached the perception threshold for this compound (4500 $\mathrm{mg} \mathrm{l}^{-1}$ ) [26].
There are no significant differences for acetoin content among tested strains even though the concentration of this compound was larger in beers from Experiment A.

Higher alcohols, also called "fusel alcohols", are the most abundant components in beer and are important flavour and aroma components in terms of their concentrations. Below $300 \mathrm{mg} \mathrm{l}^{-1}$, these compounds add complexity to the beer, by conferring refreshing, flowery, and pleasant notes, and imparting a desirable warming character [27].

For most of the volatiles analysed, the concentrations were larger in Experiment B where the worts had higher original gravity and the strains were used for bottle conditioning; 1-propanol went from $\left(4.6 \pm 0.4-8.7 \pm 0.7 \mathrm{mg} \mathrm{l}^{-1}\right)$ to $\left(29.9 \pm 0.2-35.5 \pm 3.6 \mathrm{mg} \mathrm{l}^{-1}\right)$, isobutanol increased from $\left(3.6 \pm 0.2-10.6 \pm 2.9 \mathrm{mg} \mathrm{l}^{-1}\right)$ to $\left(62.8 \pm 0.3-68.9 \pm 5.9 \mathrm{mg} \mathrm{l}^{-1}\right)$, 2-methyl-1-butanol increased from $(5.8 \pm 0.5-24.1 \pm 7.8 \mathrm{mg}$ $\left.\mathrm{1}^{-1}\right)$ to $\left(116.8 \pm 0.5-141.5 \pm 16.6 \mathrm{mg} \mathrm{l}^{-1}\right)$, 3-methyl1-butanol increased from $(2.9 \pm 0.3-10.9 \pm 3.2 \mathrm{mg}$ $\left.\mathrm{1}^{-1}\right)$ to $\left(44.7 \pm 0.1-53.2 \pm 6.0 \mathrm{mg} \mathrm{l}^{-1}\right)$ and 2-phenylethyl alcohol went from $\left(2.6 \pm 5.8-12.9 \pm 2.6 \mathrm{mg} \mathrm{l}^{-1}\right)$ to $\left(101.1 \pm 12.5-179.8 \pm 10.5 \mathrm{mg} \mathrm{l}^{-1}\right)$. With the exception of 2-phenylethyl alcohol, there are no significant differences in the concentration of higher alcohols for the strains used for bottle conditioning in Experiment B; on the other hand, there are significant differences for strains used in Experiment A, and S. cerevisiae produced the largest values.

Esters are of major industrial interest because they have very low thresholds and define the fruity aroma of the beer, with beers produced from worts containing higher percentages of both glucose and fructose and higher ester levels than those obtained from maltose-rich worts [27]. From the esters analysed (ethyl acetate, isobutyl acetate, isoamyl acetate, 2-phenylethyl acetate), the concentrations were higher in Experiment B due to the higher original gravity and the strains were used for bottle conditioning; ethyl acetate values went up from $\left(2.0 \pm 0.4-6.3 \pm 0.8 \mathrm{mg}^{-1}\right)$ to $\left(29.0 \pm 0.5-34.3 \pm 2.5 \mathrm{mg} \mathrm{l}^{-1}\right)$, isoamyl acetate increased from $\left(0-2.3 \pm 0.8 \mathrm{mg}^{-1}\right)$ to $\left(4.0 \pm 0.1-4.4 \pm 0.1 \mathrm{mg} \mathrm{l}^{-1}\right)$ 
Table 3 Concentration of volatile compounds in the beer produced by the five yeast strains in both Experiment A and B (mg $1^{-1}$ ), as determined by GC-FID

\begin{tabular}{|c|c|c|c|c|c|c|}
\hline & S. cerevisiae & S. pombe & T. delbrueckii & S. ludwigii & L. thermotolerans & Experiment \\
\hline \multirow[t]{2}{*}{ Acetaldehyde } & $14.8 \pm 10.0^{\mathrm{b}}$ & $12.9 \pm 8.4^{\mathrm{b}}$ & $2.3 \pm 0.5^{\mathrm{a}}$ & $4.2 \pm 1.4^{\mathrm{a}}$ & $4.1 \pm 1.2^{\mathrm{a}}$ & $\mathrm{A}$ \\
\hline & $5.8 \pm 0.3 \mathrm{a}$ & $20.6 \pm 2.3 b$ & $6.7 \pm 1.9 \mathrm{a}$ & $5.5 \pm 1.5 \mathrm{a}$ & $6.9 \pm 1.3 \mathrm{a}$ & B \\
\hline \multirow[t]{2}{*}{ Methanol } & $4.8 \pm 0.4^{\mathrm{ab}}$ & $4.8 \pm 0.2^{\mathrm{ab}}$ & $4.6 \pm 0.3^{\mathrm{a}}$ & $5.1 \pm 0.2^{b}$ & $4.5 \pm 0.3^{\mathrm{a}}$ & A \\
\hline & $8.2 \pm 0.2 b$ & $5.9 \pm 0.3 \mathrm{a}$ & $6.7 \pm 0.4 \mathrm{a}$ & $8.0 \pm 0.1 b$ & $6.3 \pm 0.7 \mathrm{a}$ & $\mathrm{B}$ \\
\hline \multirow[t]{2}{*}{ 1-Propanol } & $8.2 \pm 1.9^{\mathrm{b}}$ & $8.7 \pm 0.7^{\mathrm{b}}$ & $4.6 \pm 0.4^{\mathrm{a}}$ & $5.3 \pm 0.1^{\mathrm{a}}$ & $7.6 \pm 0.9^{\mathrm{b}}$ & A \\
\hline & $31.6 \pm 0.9 \mathrm{a}$ & $34.7 \pm 3.5 \mathrm{a}$ & $35.0 \pm 3.6 \mathrm{a}$ & $29.9 \pm 0.2 \mathrm{a}$ & $31.4 \pm 0.7 \mathrm{a}$ & $\mathrm{B}$ \\
\hline \multirow[t]{2}{*}{ Diacetyl } & $0.0 \pm 0.0^{\mathrm{a}}$ & $0.3 \pm 0.8^{\mathrm{a}}$ & $0.7 \pm 1.0^{\mathrm{ab}}$ & $1.9 \pm 1.1^{\mathrm{b}}$ & $0.8 \pm 1.1^{\mathrm{ab}}$ & A \\
\hline & $1.6 \pm 0.1 \mathrm{ab}$ & $1.4 \pm 0.0 \mathrm{a}$ & $1.7 \pm 0.1 \mathrm{ab}$ & $1.4 \pm 0.0 \mathrm{a}$ & $1.9 \pm 0.3 b$ & $\mathrm{~B}$ \\
\hline \multirow[t]{2}{*}{ Ethyl acetate } & $5.3 \pm 0.6^{\mathrm{c}}$ & $3.3 \pm 0.7^{\mathrm{b}}$ & $2.8 \pm 0.5^{\mathrm{ab}}$ & $2.0 \pm 0.4^{\mathrm{a}}$ & $6.3 \pm 0.8^{\mathrm{d}}$ & A \\
\hline & $29.0 \pm 0.5 \mathrm{a}$ & $31.7 \pm 3.6 \mathrm{ab}$ & $34.3 \pm 2.5 b$ & $29.4 \pm 0.7 \mathrm{a}$ & $29.5 \pm 0.8 \mathrm{ab}$ & $\mathrm{B}$ \\
\hline \multirow[t]{2}{*}{ 2-Butanol } & $0.0 \pm 0.0^{\mathrm{a}}$ & $0.0 \pm 0.0^{\mathrm{a}}$ & $0.0 \pm 0.0^{\mathrm{a}}$ & $0.0 \pm 0.0^{\mathrm{a}}$ & $0.0 \pm 0.0^{\mathrm{a}}$ & A \\
\hline & $3.4 \pm 0.1 b c$ & $3.2 \pm 0.1 \mathrm{ab}$ & $3.1 \pm 0.1 \mathrm{a}$ & $3.5 \pm 0.1 \mathrm{c}$ & $3.2 \pm 0.1 \mathrm{ab}$ & $\mathrm{B}$ \\
\hline \multirow[t]{2}{*}{ Isobutanol } & $10.6 \pm 2.9^{c}$ & $3.6 \pm 0.2^{\mathrm{a}}$ & $4.5 \pm 0.5^{\mathrm{a}}$ & $9.9 \pm 0.4^{c}$ & $7.6 \pm 0.9^{b}$ & A \\
\hline & $67.8 \pm 2.9 \mathrm{a}$ & $68.9 \pm 5.9 \mathrm{a}$ & $67.7 \pm 4.9 \mathrm{a}$ & $62.8 \pm 0.3 a$ & $63.3 \pm 0.6 \mathrm{a}$ & $\mathrm{B}$ \\
\hline \multirow[t]{2}{*}{ 1-Butanol } & $5.4 \pm 5.4^{\mathrm{b}}$ & $1.6 \pm 3.5^{\mathrm{ab}}$ & $1.2 \pm 2.7^{\mathrm{ab}}$ & $0.0 \pm 0.0^{\mathrm{a}}$ & $5.3 \pm 5.0^{\mathrm{b}}$ & A \\
\hline & $4.3 \pm 0.1 \mathrm{a}$ & $4.5 \pm 0.1 b c$ & $4.6 \pm 0.1 \mathrm{c}$ & $4.4 \pm 0.1 \mathrm{ab}$ & $4.4 \pm 0.0 \mathrm{abc}$ & $\mathrm{B}$ \\
\hline \multirow[t]{2}{*}{ Acetoín } & $8.4 \pm 0.2^{\mathrm{a}}$ & $8.8 \pm 0.1^{\mathrm{a}}$ & $8.6 \pm 0.1^{\mathrm{a}}$ & $8.7 \pm 0.3^{\mathrm{a}}$ & $7.0 \pm 3.9^{\mathrm{a}}$ & A \\
\hline & $5.5 \pm 0.0 \mathrm{a}$ & $5.6 \pm 0.1 \mathrm{a}$ & $5.4 \pm 0.1 \mathrm{a}$ & $5.5 \pm 0.1 \mathrm{a}$ & $5.5 \pm 0.1 \mathrm{a}$ & $\mathrm{B}$ \\
\hline \multirow[t]{2}{*}{ 2-Methyl-1-butanol } & $24.1 \pm 7.8^{c}$ & $5.8 \pm 0.5^{\mathrm{a}}$ & $7.2 \pm 1.1^{\mathrm{a}}$ & $10.0 \pm 0.3^{\mathrm{a}}$ & $17.8 \pm 2.7^{\mathrm{b}}$ & A \\
\hline & $126.7 \pm 4.2 \mathrm{a}$ & $133.0 \pm 14.7 \mathrm{a}$ & $141.5 \pm 16.6 \mathrm{a}$ & $116.8 \pm 0.5 a$ & $123.6 \pm 2.7 \mathrm{a}$ & B \\
\hline \multirow[t]{2}{*}{ 3-Methyl-1-butanol } & $10.9 \pm 3.2^{\mathrm{d}}$ & $2.9 \pm 0.3^{\mathrm{a}}$ & $3.1 \pm 0.3^{\mathrm{ab}}$ & $5.0 \pm 0.3^{\mathrm{bc}}$ & $5.6 \pm 0.8^{\mathrm{c}}$ & A \\
\hline & $47.9 \pm 1.5 \mathrm{a}$ & $51.6 \pm 5.1 \mathrm{a}$ & $53.2 \pm 6.0 \mathrm{a}$ & $44.7 \pm 0.1 \mathrm{a}$ & $46.6 \pm 1.2 \mathrm{a}$ & B \\
\hline \multirow[t]{2}{*}{ Ethyl lactate } & $0.0 \pm 0.0^{\mathrm{a}}$ & $0.0 \pm 0.0^{\mathrm{a}}$ & $0.0 \pm 0.0^{\mathrm{a}}$ & $0.0 \pm 0.0^{\mathrm{a}}$ & $0.0 \pm 0.0^{\mathrm{a}}$ & A \\
\hline & $5.6 \pm 0.0 \mathrm{a}$ & $5.6 \pm 0.0 \mathrm{a}$ & $5.7 \pm 0.1 \mathrm{a}$ & $5.6 \pm 0.0 \mathrm{a}$ & $5.6 \pm 0.0 \mathrm{a}$ & $\mathrm{B}$ \\
\hline \multirow[t]{2}{*}{ 2,3-Butanediol } & $0.0 \pm 0.0^{\mathrm{a}}$ & $0.0 \pm 0.0^{\mathrm{a}}$ & $63.0 \pm 58.0^{\mathrm{b}}$ & $67.8 \pm 37.9^{\mathrm{b}}$ & $72.1 \pm 40.8^{b}$ & A \\
\hline & $278.1 \pm 8.9 a$ & $291.7 \pm 19.4 a$ & $295.5 \pm 14.6 \mathrm{a}$ & $265.5 \pm 5.4 a$ & $287.2 \pm 8.3 \mathrm{a}$ & $\mathrm{B}$ \\
\hline \multirow[t]{2}{*}{ Isoamyl acetate } & $0.0 \pm 0.0^{\mathrm{a}}$ & $0.0 \pm 0.0^{\mathrm{a}}$ & $2.3 \pm 4.1^{\mathrm{a}}$ & $0.0 \pm 0.0^{\mathrm{a}}$ & $0.0 \pm 0.0^{\mathrm{a}}$ & A \\
\hline & $4.3 \pm 0.1^{\mathrm{a}}$ & $4.1 \pm 0.3^{\mathrm{a}}$ & $4.4 \pm 0.1^{\mathrm{a}}$ & $4.0 \pm 0.1^{\mathrm{a}}$ & $4.3 \pm 0.1^{\mathrm{a}}$ & $\mathrm{B}$ \\
\hline \multirow[t]{2}{*}{ 2-Phenylethyl alcohol } & $12.9 \pm 2.6^{\mathrm{c}}$ & $7.1 \pm 4.1^{\mathrm{abc}}$ & $9.5 \pm 1.7^{\mathrm{bc}}$ & $5.5 \pm 8.2^{\mathrm{ab}}$ & $2.6 \pm 5.8^{\mathrm{a}}$ & A \\
\hline & $179.8 \pm 10.5 b$ & $101.1 \pm 12.5 \mathrm{a}$ & $177.2 \pm 36.8 b$ & $167.4 \pm 9.0 \mathrm{~b}$ & $176.6 \pm 3.5 b$ & $\mathrm{~B}$ \\
\hline \multirow[t]{2}{*}{ 2-Phenylethyl acetate } & $0.0 \pm 0.0^{\mathrm{a}}$ & $5.5 \pm 0.7^{b}$ & $4.4 \pm 4.2^{\mathrm{b}}$ & $6.6 \pm 0.9^{\mathrm{b}}$ & $5.3 \pm 0.3^{\mathrm{b}}$ & A \\
\hline & $10.9 \pm 1.2 \mathrm{~b}$ & $7.1 \pm 0.1 \mathrm{a}$ & $11.5 \pm 1.0 \mathrm{~b}$ & $9.1 \pm 0.3 \mathrm{ab}$ & $10.4 \pm 0.4 b$ & $\mathrm{~B}$ \\
\hline
\end{tabular}

Data are means \pm standard deviations

Data with different superscript letters within each file are significantly different (Tukey tests: $P<0.05$ ); A: the same yeast strain was inoculated in both primary fermentation and bottle conditioning. B: S. cerevisiae Florapan A18 in primary fermentation. The bottle conditioning with the five yeast strains

and 2-phenylethyl acetate increased concentration from $\left(0-6.6 \pm 0.9 \mathrm{mg} \mathrm{l}^{-1}\right)$ to $\left(7.1 \pm 0.1-11.5 \pm 1 \mathrm{mg} \mathrm{l}^{-1}\right)$. Regarding yeast strain influence, the production of ethyl acetate was below threshold $\left(30 \mathrm{mg} \mathrm{l}^{-1}\right)$ of beers produced in Experiment A.

In order to better illustrate these results, a multivariate statistical analysis was carried out. The PCA was performed on the entire database, which included the level of the volatile compounds analysed for all strains used in the study. In this case, the higher alcohols were combined for each strain tested across each of the two experiments. The first two principal components explained most of the variance
(94\%). Only first principal component (PC1) covered 79.3\% of the variation in the data, summarized in the following equation: $0,34 *$ ethanol $+0,01 *$ acetaldehyde $+0,26 *$ diacetyl $+0,35 *$ ethyl acetate $-0,34 *$ acetoin $+0,35 *$ ethyl lactate $+0,35 * 2,3$ - butanediol $+0,33 *$ Isoamyl acetate $+0,31 * 2-$ phenylethanol $+0,35 *$ higher alcohols - hexanol.

Four main groups could be clearly differentiated (Fig. 2). Two of these sit on the positive part of the component 1 axis, and represent those beers obtained in Experiment B, with higher original gravity worts inoculated with $S$. cerevisiae Florapan A18 in primary fermentation and 


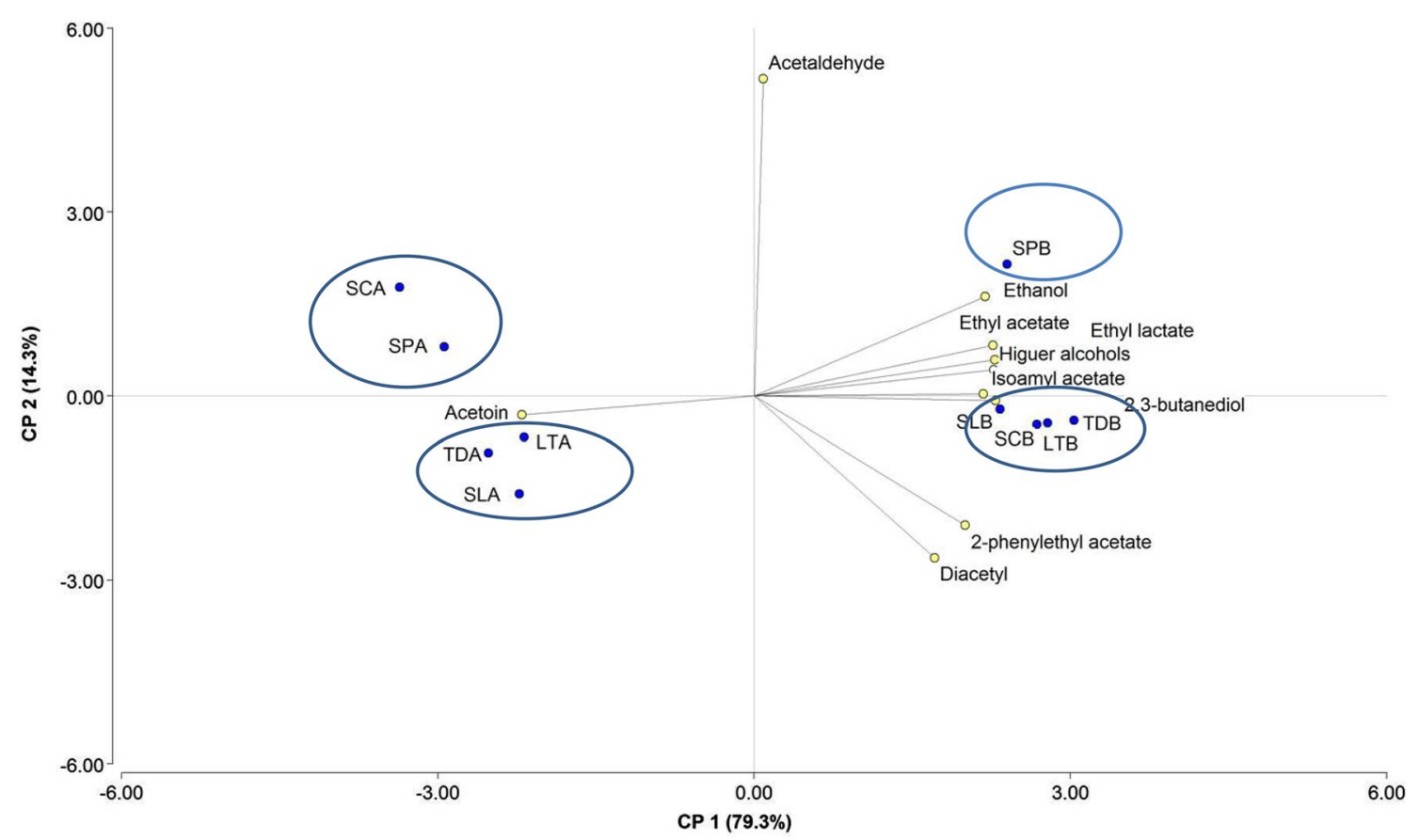

Fig. 2 Principal component analysis (PCA) of volatile compounds in the beer produced by the five yeast strains in both Experiment $\mathrm{A}$ and B $\left(\mathrm{mg}^{-1}\right)$, by GC/MS. SCA S. cerevisiae 7VA Experiment A, SPA Schizo. pombe Experiment A, TDA T. delbrueckii Experiment A, LTA L. thermotolerans Experiment A, SLA S. ludwigii Experiment A, $S C B$ S.cerevisiae 7VA Experiment B, SPB Schizo. pombe Experiment

bottle conditioning with non-Saccharomyces yeasts in bottle. These beers exhibit the highest production of higher alcohols, esters and aldehydes. It can be seen for the beer where $S$. pombe was used for bottle conditioning, that the profile is clearly different from the rest of the beers which are more similar to each other.

The other two groups sit on the negative part of the axis, and represent those beers obtained in Experiment A. One of these represents those beers obtained from S. pombe and $S$. cerevisiae yeast strains (positive side of component 2 ), and the other includes the other 3 non-Saccharomyces yeast beers (negative side of component 2). Beers with the $S$. pombe yeast strain in Experiment A also appear on the positive side of component 2 (right top quadrant on the biplot) related to higher acetaldehyde production and lower $\mathrm{pH}$ values in both experiments. Although T. delbrueckii, L. thermotolerans and S. ludwigii are grouped on the negative axis, their position on the chart, distance between them, represents less similarity between them than the results observed in Experiment B; this reinforces the evidence of having more pronounced differences when the yeast strains are used for the fermentation and the bottle conditioning.

Sensory analysis. The beers obtained in Experiment A (primary fermentation and bottle conditioning with the five different yeast strains) and in Experiment B (yeast S.
B, TDB T. delbrueckii Experiment B, LTB L. thermotolerans Experiment B, SLB S. ludwigii Experiment B. Experiment A: the same yeast strain was inoculated in both primary fermentation and bottle conditioning. Experiment B: S. cerevisiae Florapan A18 in primary fermentation. The bottle conditioning with the five yeast strains

cerevisiae Florapan A18 inoculated in primary fermentation and bottle conditioning with the five different yeast strains) underwent sensory analysis, with data illustrated in Fig. 3.

\section{Discussion}

The production of quality beer depends not only on good yeast fermentation efficiency, but also on the characteristic aroma and flavours that yeast can provide to the final product [27]. Five different species of different genera have been evaluated in this study (four non-Saccharomyces and S. cerevisiae as control); the differences in beer aromas found in final product, across the different trials, have been evaluated analytically and for sensory attributes.

Beers obtained from fermentations with $S$. pombe had the highest ethanol content in both experiments. This could be related to how organic acids are metabolized by yeast species other than $S$. cerevisiae. It could also be related to the high ability that the yeast species $S$. pombe has to ferment maltose, being the most abundant sugar available in beer wort at ca. 60\% [28]. Linder initially isolated the species S. pombe in 1893 in East Africa and it is able to metabolize malic acid across the maloalcoholic (MA) fermentation pathway with ethanol and $\mathrm{CO}_{2}$ as final products instead of 

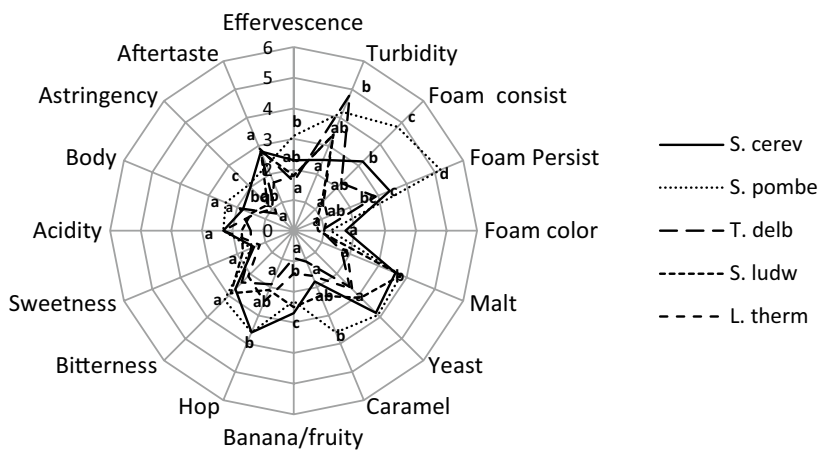

Fig. 3 Spider net graph for sensory analysis results. Values are the means for nine independent tasters. Different letters in the same series indicate significant differences between means $(p<0.05)$ Left: Experiment (A) Right: Experiment (B) Experiment A: the same yeast strain

lactic acid like in the bacterial malolactic fermentation. This peculiar yeast has been traditionally used in some areas of Africa in the production of mijo beer [9]. Pombe means beer in the Swahili language.

At the same time, beers produced with $S$. cerevisiae and $S$. pombe, both yeast strains able to ferment maltose, have achieved the highest acetaldehyde concentration (green aroma, herbal) when used as pure culture fermentative strains (Experiment A) with values between 12.9 and $14.8 \mathrm{mg}^{-1}$, although higher values were obtained with $S$. pombe when this species was used for bottle conditioning $\left(20.6 \mathrm{mg} \mathrm{l}^{-1}\right)$. Acetaldehyde has a flavour threshold of $10-20 \mathrm{mg} \mathrm{l}^{-1}$ and its presence in beer above threshold values result in 'grassy' off-flavours [29]. However, many tasters can detect this compound at much lower levels.

Beers produced with $T$. delbrueckii and S. ludwigii had the significantly lowest ethanol content in Experiment A. The species S. ludwigii is developed more for low-alcohol beer production since it does not ferment maltose and maltotriose [12, 24, 30]; although it has been seen to consume maltose but much slower in comparison to the species $S$. cerevisiae [13, 31]. The suitability of different strains of $T$. delbrueckii in pure cultures to produce low-alcohol beers has also been demonstrated [32, 33]. In this body of research, $T$. delbrueckii produced the greatest concentration of isoamyl acetate in Experiment A, with isoamyl acetate being perhaps the most important ester, owing to its very low flavour threshold [4]. Traditionally, T. delbrueckii has been used in the production of German-style wheat beers (Hefeweizen) for its banana, bubble-gum, and clove-like flavours [12]; it has also been considered for brewing because of its ability to enhance flavour and to reduce ethanol content.

During wine fermentation, $T$. delbrueckii yeast strains produce noticeably higher concentrations of higher alcohols, esters, terpenes and phenolic aldehydes as well as other molecules including 2-phenyl ethanol, linalool, methylvanillin

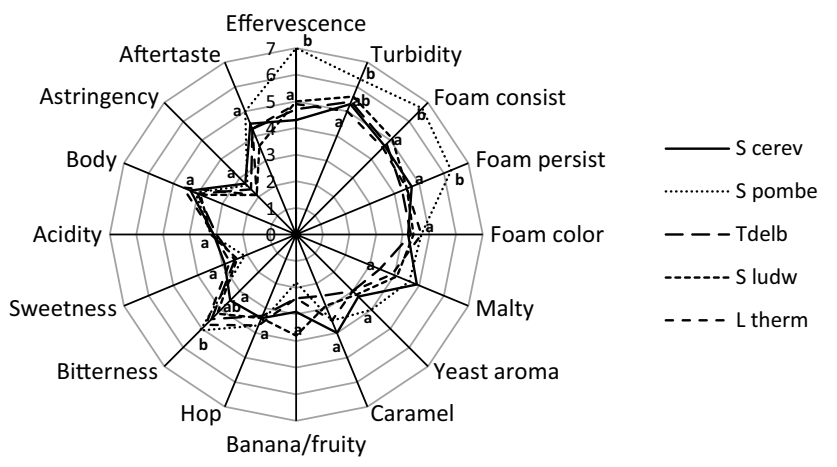

was inoculated in both primary fermentation and bottle conditioning. Experiment B: S. cerevisiae Florapan A18 in primary fermentation. The bottle conditioning with the five yeast strains

[13]. In Experiment B, this yeast species produced the highest concentration of ethyl acetate $\left(34.3 \mathrm{mg}^{-1}\right)$ above threshold $\left(30 \mathrm{mg} \mathrm{l}^{-1}\right)$ [34]. Regarding the content of ethyl lactate, no evidence of this ester was found in beers of trial A. Nevertheless, first principal component (PC1) was characterized by high positive values for ethyl lactate $(35 \%)$ variation in the data, this underlines the importance of ethyl lactate in the separation into two groups by PC1.

With the exception of beer brewed with $S$. cerevisiae in Experiment A, diacetyl concentrations were strikingly high for all beers. L. thermotolerans in Experiment B and S. ludwigii in Experiment A produced higher concentrations of diacetyl $\left(1.9 \mathrm{mg} \mathrm{l}^{-1}\right)$. Diacetyl gives wine a buttery and nutty aroma, but in some lighter-flavoured lager are considered undesirable above threshold levels. Concentrations of diacetyl higher than those found in our study in non-Saccharomyces yeasts were previously reported by $S$ ludwigii by Escott et al. (2016) [35], and T. delbrueckii by Loira et al. [19], both in wine production. A concentration of $0.8 \mathrm{ppm}$ of diacetyl in beer was reported for Zygosaccharomyces rouxii by De Francesco et al. 2015 [36]. Diacetyl is a vicinal diketone produced as a by-product of yeast valine metabolism during fermentation. In beer conditioning, yeasts reduce diacetyl to the much less flavour-active acetoin and 2,3-butanediol. The high levels of diacetyl found in this study in general can be related to the low capacity to reduce the high amounts of this compound, during bottle or cask conditioning, which has been described by Basso et al. [11] for T. delbrueckii. The sensory evaluation did not result in a negative perception regarding this compound.

Even though some authors have validated that beer fermented by $S$. ludwigii tends to be sweet due to its high residual maltose and maltotriose content, no differences were perceived sensory wise among the tested beers in any of the Experiments (A and B) tentatively due to the relative sweetness of these sugars that is significantly lower than 
that of sucrose and glucose. As pure culture [24], S. ludwigii obtained isobutanol concentrations of up to $9.9 \pm 0.4 \mathrm{mg} \mathrm{l}^{-1}$ in Experiment A, similar to those analysed by Francesco et al. [36] after testing 11 non-conventional yeast strains for low-alcohol beer production. This confirms that $S$. ludwigii is more suitable for brewing low-alcohol content beer.

Ethanol production had no significant difference for strains L. thermotolerans and S. cerevisiae. In Experiment A, principal fermentation and bottle conditioning with the same strain, $\mathrm{pH}$ value for beer produced with the species $L$. thermotolerans was higher than that produced with S. cerevisiae despite the fact that Domizio et al. [16] suggested that pure culture beer fermentation by $L$. thermotolerans may be a good choice for producing sour beers since they lowered the $\mathrm{pH}$ more than in beers fermented with Saccharomyces spp.

Concerning sensory analysis, the beers produced in Experiment B obtained the highest scores for most of the parameters evaluated; this could be related to an attenuation phenomenon and higher alcohol content produced in these beers from musts with greater original gravity.

The highest score for consistency and persistence of foam was obtained by $S$. pombe (Fig. 2), a yeast with a greater fermentative power (higher $\mathrm{CO}_{2}$ production) and a cell wall structure that following autolysis releases mannoproteins and polysaccharides [20,37], compounds related to in the consistency and persistence of the foam [38]. There are more differences perceived in aroma attributes among strains in Experiment A.

\section{Conclusions}

Although the original wort was different for both experimental designs, beers produced with $S$. pombe were notably differentiated from the other evaluated strains in each experiment. In general, esters and higher alcohols achieved higher global values when the original gravity of the wort was also higher and, the fermentative strains were used for bottle conditioning. Nevertheless, the differences in concentration of the volatiles produced were more pronounced when the yeast strain under study was used for both, the fermentation and the bottle conditioning (first experiment setup) than when it was used just for the bottle conditioning (second experiment setup). The high levels of diacetyl generally found in the beers in this study could be related to the low capacity to reduce the high amounts of this compound during bottle or cask conditioning The species $T$. delbrueckii and S. ludwigii, followed by L. thermotolerans, are prone to producing low ethanol content beers with characteristic aroma profiles, while $S$. pombe may increase ethanol and acetaldehyde content and, at the same time, enhance foam consistency and persistence. In this way, and in line with the results assessed during this experimental body of research, it is possible to tackle different industrial approaches for beer production where non-Saccharomyces yeasts may play an important role.

\section{Compliance with ethical standards}

Conflict of interest The authors declare that there are no conflicts of interest.

Compliance with ethics requirements This article does not contain any studies with human or animal subjects.

\section{References}

1. Gómez-Corona C, Escalona-Buendía HB, García M, Chollet S, Valentin D (2016) Craft vs. industrial: habits, attitudes and motivations towards beer consumption in Mexico. Appetite 96:358-367

2. Verstrepen KJ, Derdelinckx G, Dufour JP, Winderickx J, Thevelein JM, Pretorius IS, Delvaux FR (2003) Flavor-active esters: adding fruitiness to beer. J Biosci Bioeng 96(2):110-118

3. Pires EJ, Teixeira JA, Brányik T, Vicente AA (2014) Yeast: the soul of beer's aroma-a review of flavour-active esters and higher alcohols produced by the brewing yeast. Appl Microbiol Biotechnol 98(5):1937-1949

4. Bokulich NA, Bamforth CW (2013) The microbiology of malting and brewing. Microbiol Mol Biol Rev 77(2):157-172

5. Canonico L, Comitini F, Ciani M (2014) Dominance and influence of selected Saccharomyces cerevisiae strains on the analytical profile of craft beer refermentation. J Inst Brew 120(3):262-267

6. Capozzi Capozzi V, Makhoul S, Aprea E, Romano A, Cappellin L, Jimena SA, Biasioli F et al (2016) PTR-MS characterization of VOCs associated with commercial aromatic bakery yeasts of wine and beer origin. Molecules 21(4):483

7. Mascia I, Fadda C, Dostálek P, Karabín M, Zara G, Budroni M, Del Caro A (2015) Is it possible to create an innovative craft durum wheat beer with sourdough yeasts? A case study. J Inst Brew 121(2):283-286

8. Marongiu A, Zara G, Legras JL, Del Caro A, Mascia I, Fadda C, Budroni M (2015) Novel starters for old processes: use of Saccharomyces cerevisiae strains isolated from artisanal sourdough for craft beer production at a brewery scale. J Ind Microbiol Biotechnol 42(1):85-92

9. Callejo MJ, González C, Morata A (2017) Use of non-Saccharomyces yeasts in bottle fermentation of aged beers. In Brewing Technology. InTech

10. Yeo HQ, Liu SQ (2014) An overview of selected specialty beers: developments, challenges and prospects. Int J Food Sci Technol 49(7):1607-1618

11. Basso RF, Alcarde AR, Portugal CB (2016) Could non-Saccharomyces yeasts contribute on innovative brewing fermentations? Food Res Int 86:112-120

12. Petruzzi L, Rosaria Corbo M, Sinigaglia M, Bevilacqua A (2016) Brewer's yeast in controlled and uncontrolled fermentations, with a focus on novel, nonconventional, and superior strains. Food Rev Int 32(4):341-363

13. Tataridis P, Kanelis A, Logotetis S, Nerancis E (2013) Use of non-Saccharomyces Torulaspora delbrueckii yeast strains in winemaking and brewing. Zbornik Matice srpske za prirodne nauke $124: 415-426$ 
14. Comitini F, Gobbi M, Domizio P, Romani C, Lencioni L, Mannazzu I, Ciani M (2011) Selected non-Saccharomyces wine yeasts in controlled multistarter fermentations with Saccharomyces cerevisiae. Food Microbiol 28:873-882. https://doi.org/10.1016/j. fm.2010.12.001

15. Gobbi M, Comitini F, Domizio P, Romani C, Lencioni L, Mannazzu I, Ciani M (2013) Lachancea thermotolerans and Saccharomyces cerevisiae in simultaneous and sequential co-fermentation: a strategy to enhance acidity and improve the overall quality of wine. Food Microbiol 33:271-281. https://doi.org/10.1016/j. fm.2012.10.004

16. Domizio P, House JF, Joseph CML, Bisson LF, Bamforth CW (2016) Lachancea thermotolerans as an alternative yeast for the production of beer. J Inst Brew 122(4):599-604

17. Loira I, Morata A, Comuzzo P, Callejo MJ, González C, Calderón F, Suárez-Lepe JA (2015) Use of Schizosaccharomyces pombe and Torulaspora delbrueckii strains in mixed and sequential fermentations to improve red wine sensory quality. Food Res Int 76:325-333

18. Morata A, Benito S, Loira I, Palomero F, González MC, SuárezLepe JA (2015) Formation of pyranoanthocyanins by Schizosaccharomyces pombe during the fermentation of red must. Food Res Int 76:325-333

19. Loira I, Vejarano R, Bañuelos MA, Morata A, Tesfaye W, Uthurry C, Villa A, Cintora I, Suárez-Lepe JA (2014) Influence of sequential fermentation with Torulaspora delbrueckii and Saccharomyces cerevisiae. on wine quality. LWT Food Sci Technol 59:915-922

20. Palomero F, Morata A, Benito S, Calderón F, Suárez-Lepe JA (2009) New genera of yeasts for over-lees aging of red wine. Food Chem 112:432-441

21. Morata A, Loira I, Tesfaye W, Bañuelos MA, González C, Suárez Lepe JA (2018) Lachancea thermotolerans applications in wine technology. Rev Ferment 4:53. https://doi.org/10.3390/fermentati on 4030053

22. ISO 6564 (1985) Sensory analysis. flavour profile methods. International Organization for Standardization, Geneva

23. ISO 4121 (2003) Sensory analysis. Evaluation of food products by methods using scales. International Organization for Standardization, Geneva

24. Brányik T, Silva D, Baszczynski M, Lehnert R (2012) Almeida e Silva. A review of methods of low alcohol and alcohol-free beer production. J Food Eng 108:493-506

25. Polshin E, Rudnitskaya A, Kirsanov D, Legin A, Saison D, Delvaux F, Delvaux F, Nicolaï B, Lammertyn J (2010) Electronic tongue as a screening tool for rapid analysis of beer. Talanta 81:88-94

26. Tan Y, Siebert KJ (2004) Quantitative structure-activity relationship modeling of alcohol, ester, aldehyde, and ketone flavor thresholds in beer from molecular features. J Agric Food Chem 52(10):3057-3064

27. Budroni M, Zara G, Ciani M, Comitini F (2017) Saccharomyces and non-saccharomyces starter yeasts. In Brewing Technology. InTech

28. Magalhães F, Vidgren V, Ruohonen L, Gibson B (2016) Maltose and maltotriose utilisation by group I strains of the hybrid lager yeast Saccharomyces pastorianus. FEMS Yeast Res 16(5):1-11

29. Meilgaard M (1975) Flavour chemistry of beer. Part 2. Flavour and threshold of 239 aroma volatiles. Tech Q Master Brew Assoc Am 12:151-168

30. Montanari L, Marconi O, Mayer H, Fantozzi P (2009) Production of alcohol-free beer. In: Preedy V (ed) Beer in health and disease prevention. Academic Press, Cambridge, pp 61-75

31. Alves-Araujo C, Pacheco A, Almeida MJ, Spencer-Martins I, Leao C, Sousa MJ (2007) Sugar utilization patterns and respiro-fermentative metabolism in the baker's yeast Torulaspora delbrueckii. Microbiology 153:898-904

32. Canonico L, Agarbati A, Comitini F, Ciani M (2016) Torulaspora delbrueckii in the brewing process: a new approach to enhance bioflavour and to reduce ethanol content. Food Microbiol 56:45-51

33. Michel M, Kopecká J, Meier-Dörnberg T, Zarnkow M, Jacob F, Hutzler M (2016) Screening for new brewing yeasts in the nonSaccharomyces sector with Torulaspora delbrueckii as model. Yeast 33(4):129-144

34. Hughes PS, Baxter ED (2003) Cerveza. Calidad, higiene y características nutricionales. Ed. Acribia, Zaragoza

35. Escott C, Morata A, Loira I, Tesfaye W, Suarez-Lepe JA (2016) Characterization of polymeric pigments and pyranoanthocyanins formed in microfermentations of non-Saccharomyces yeasts. $\mathrm{J}$ Appl Microbiol 121(5):1346-1356

36. De Francesco G, Turchetti B, Sileoni V, Marconi O, Perretti G (2015) Screening of new strains of Saccharomycodes ludwigii and Zygosaccharomyces rouxii to produce low-alcohol beer. J Inst Brew 121(1):113-121

37. Suárez-Lepe JA, Palomero F, Benito S, Calderón F, Morata A (2012) Oenological versatility of Schizosaccharomyces spp. Eur Food Res Technol 235:375-383

38. Schmidt T, Kluba R (2002) Calidad de cerveza y metodología para catar. In: Jurado J, Russell I (eds) El cervecero en la práctica (427-456). Master Brewers Association of the Americas, St. Paul

Publisher's Note Springer Nature remains neutral with regard to jurisdictional claims in published maps and institutional affiliations. 